\title{
ANTIPREDATOR VIGILANCE IN COOPERATIVELY BREEDING SUPERB FAIRY-WRENS (MALURUS CYANEUS)
}

\author{
Ken Yasukawa ${ }^{1}$ and Andrew COCKBurn \\ School of Botany and Zoology, Australian National University, Canberra, ACT 0200, Australia
}

\begin{abstract}
We studied 19 color-banded groups of the cooperatively breeding Superb Fairy-wren (Malurus cyaneus) to determine (1) the contributions of breeding and helper males to antipredator vigilance, (2) whether such vigilance reduces predation risk, and (3) the mechanisms by which it might do so. Time spent as a sentinel (perching and scanning from conspicuous locations within sight of the nest) increased with group size, but successful and depredated nests did not differ significantly in sentinel time, and sentinels did not appear to coordinate their vigilance. Both breeder and helper males acted as sentinels, and both were more vigilant when nests contained nestlings than when they contained eggs. Breeders with helpers spent more time as sentinels than those without helpers. Presence of a sentinel reduced the time feeding adults spent pausing to scan when approaching and leaving the nest. Thus, vigilance could enable a male to detect a predator and decoy it away from the nest site or prevent it from locating the nest by deferring feeding visits of other provisioners, but we could not demonstrate that it reduced nest predation by the major nest predator, the Pied Currawong (Strepera graculina). Received 30 April 2008, accepted 15 September 2008.
\end{abstract}

Key words: antipredator behavior, cooperative breeding, Malurus cyaneus, parental behavior, Superb Fairy-wren.

\section{Vigilancia Contra Depredadores en la Especie con Cría Cooperativa Malurus cyaneus}

ReSUMEN.-Estudiamos 19 grupos de la especie con cría cooperativa Malurus cyaneus marcados con anillos de colores para determinar (1) las contribuciones de los machos reproductores y ayudantes a la vigilancia contra depredadores, (2) si dicha vigilancia reduce el riesgo de depredación y (3) los mecanismos a través de los cuales podría reducirlo. El tiempo invertido por los individuos como centinelas (perchados y realizando barridos visuales desde ubicaciones conspicuas en las que los nidos podían ser observados) aumentó con el tamaño de los grupos, pero los nidos exitosos y los depredados no difirieron significativamente en el tiempo de vigilancia, y los centinelas no parecieron coordinar sus actividades de vigilancia. Tanto los machos reproductores como los ayudantes actuaron como centinelas y ambos fueron más vigilantes cuando los nidos contenían pichones que cuando contenían huevos. Los reproductores que tenían ayudantes pasaron más tiempo como centinelas que los que no los tenían. La presencia de un centinela redujo el tiempo en el que los adultos alimentadores realizaron pausas para hacer barridos visuales al acercarse al nido y al abandonarlo. Por lo tanto, la vigilancia le podría permitir a un macho detectar a un depredador y distraerlo para que se desplace lejos del sitio de anidación o prevenir que éste encuentre el nido retrasando las visitas de alimentación de otros aprovisionadores. Sin embargo, no pudimos demostrar que la vigilancia reduzca la depredación de nidos por parte de Strepera graculina, el principal depredador de nidos.

COOPERATIVE BREEDING SYSTEMS in which offspring receive care from parents and supernumerary "helpers" are of interest to ornithologists because, among other reasons, these systems provide opportunities to examine direct and indirect fitness costs and benefits (e.g., Stacey and Koenig 1990, Emlen 1995, Griffin and West 2003, Cockburn et al. 2008b). For example, helpers may allow breeders to make tradeoffs between current and future reproductive benefits by reducing their investments in current broods, the breeders thereby increasing their own survival and their total, lifetime number of breeding attempts (e.g., Russell et al. 2007, Cockburn et al. 2008b). Helpers are also thought to experience reproductive tradeoffs, such as paying (helping) to stay on the natal territory (e.g., Emlen and Wrege 1992) and thereby avoiding the cost of dispersal (e.g., Mulder and Langmore 1993).

Helping has been studied in many taxa (e.g., Dugatkin 1997), but most of the research has been focused on birds (e.g., Cockburn 1998). Helpers typically provide extra food (e.g., Woolfenden 1975 , Stacey and Koenig 1990), but less is known about the contribution

${ }^{1}$ Present address: Department of Biology, Beloit College, 700 College Street, Beloit, Wisconsin 53511, USA.

E-mail: yasukawa@beloit.edu

The Auk, Vol. 126, Number 1, pages 147-154. ISSN 0004-8038, electronic ISSN 1938-4254. @ 2009 by The American Ornithologists' Union. All rights reserved. Please direct all requests for permission to photocopy or reproduce article content through the University of California Press's Rights and Permissions website, http://www.ucpressjournals. com/reprintInfo.asp. DOI: 10.1525/auk.2009.08074 
of helpers to antipredator vigilance (e.g., McGowan and Woolfenden 1989, Hailman et al. 1994, Bednekoff and Woolfenden 2003). This lack of information is curious, given the long-standing interest in the effect of grouping on vigilance and predation risk of foraging animals (e.g., Pulliam 1973, Caraco 1982, Bednekoff and Lima 1998, Hollén et al. 2008).

In some species of birds that live in groups, antipredator vigilance is performed by sentinels (e.g., McGowan and Woolfenden 1989, Hailman et al. 1994, Hollén et al. 2008), which scan for predators to guard other group members and alert them to danger, and which take turns on guard (Goodwin 1976). Hailman et al. (1994) tested the hypothesis that helpers contribute to antipredator sentinel behavior in the cooperatively breeding Florida ScrubJay (Aphelocoma c. coerulescens) by examining four predictions: (1) helpers act as sentinels, (2) breeding pairs with helpers spend less time as sentinels than pairs without helpers, (3) breeders with helpers have more protected foraging time than breeders without helpers, and (4) groups with helpers have greater total sentinel time than groups without helpers. McGowan and Woolfenden (1989) also studied antipredator vigilance in the Florida Scrub-Jay to test the hypothesis that group members coordinate their sentinel behavior. These authors examined the prediction that sentinels avoid overlapping their bouts of vigilance. We attempted to determine (1) the contributions of breeding and helper males to antipredator vigilance, (2) whether such vigilance reduces the risk of predation, and (3) the mechanisms by which vigilance might reduce predation in the cooperatively breeding Superb Fairy-wren (Malurus cyaneus), a well-studied species endemic to southeastern Australia.

Superb Fairy-wrens are common in eucalypt woodland, open forest, and suburban parks and gardens in southeast Australia. They are sedentary, territorial, and multiple-brooded (Rowley 1965). Many aspects of their cooperative breeding system have been studied, including the roles of breeders and helpers, reproductive tradeoffs, and parentage (e.g., Mulder et al. 1994; Dunn et al. 1995; Dunn and Cockburn 1996; Double et al. 1997, 2005; Double and Cockburn 2000). Superb Fairy-wrens have many nest predators (Rowley 1965). At our study site, the most important is the Pied Currawong (Strepera graculina; hereafter "currawong") (Major et al. 1996, Prawiradilaga 1996). Currawongs are visual predators that perch quietly and observe the activity of potential prey. If they detect activity at a nest site, they then search the location carefully. We have observed currawongs walking slowly near active nests, stopping to inspect each potential nest site, and often finding the nest and consuming the eggs or nestlings. Given the foraging method of this important predator, it seemed that selection would favor adaptations to detect predators and to reduce the cues predators might use to locate active nests.

We observed a color-marked population of Superb Fairywrens at the Australian National Botanic Gardens to test seven predictions of the hypotheses that antipredator vigilance is a form of parental care within the cooperative breeding system of this species. (1) All male members of the breeding group act as sentinels. (2) Antipredator vigilance is associated primarily with the presence of nestlings, because provisioning by the conspicuous males is a cue that predators could use to locate the nest. (3) The total amount of vigilance increases with group size. (4) Breeding males with helpers spend less time as sentinels than pairs without helpers. (5) Nests that produce fledglings (successful nests) are guarded more than nests that are preyed upon (unsuccessful nests). (6) Presence of a sentinel facilitates feeding by other provisioners. And (7) the probability of ending a bout is independent of its length (i.e., bouts are of unpredictable, random duration), and sentinels coordinate their vigilance to provide efficient coverage.

\section{Methods}

Our study area was the Australian National Botanic Gardens $\left(35^{\circ} 06^{\prime} \mathrm{S}, 149^{\circ} 06^{\prime} \mathrm{E}\right)$ in Canberra, Australian Capital Territory, Australia. Since 1988, nearly every individual on the study area has been captured, measured, and color-banded for individual recognition. During November and December 1993, we observed the sentinel behavior of male Superb Fairy-wrens in 19 breeding groups with active nests. In each 60-min observation, a male was recorded as acting as a sentinel if he perched at a conspicuous location where he could see the nest (usually within $5 \mathrm{~m}$ ) and maintained an alert posture while he scanned the area (i.e., was not foraging or engaged in another activity). Starting and ending times and the identity of the sentinel were recorded for each sentinel bout. Although Eastern Brown Snakes (Psuedonaja textilis) occasionally take nestlings, direct observations and recovery of bands from regurgitated pellets on our study area have shown that the currawong is the principal diurnal predator of Superb Fairywren nestlings. Nocturnal predation was rare, primarily as a result of efforts to control mammalian predators. We observed breeding groups throughout the day to cover the times when currawongs were active.

We also observed provisioners as they foraged and as they approached and departed from the nest. Foraging was characterized by frequent short flights (usually $<0.5 \mathrm{~m}$ ) interspersed with rapid hopping over the substrate and looking down at the ground or branch (foraging and sentinel behavior were incompatible activities). Observation of male and female provisioners as they approached and departed from the nest allowed us to record any pauses and any vigilance behavior that occurred en route.

Male status within the breeding group was determined by age, given that males form an orderly queue for dominant status (Cockburn et al. 2008a). We categorized each male as a "breeding male" (paired with the breeding female) or a "helper male." Classification as a breeding male did not signify that the male sired the young produced by the breeding female, however. Superb Fairywrens are known to have exceptionally high rates of extrapair fertilization (Dunn and Cockburn 1996; Double et al. 1997, 2005). Breeding males were further subdivided into "pair males" (no helpers) and "dominant males" (at least one helper).

To assess the effect of sentinel behavior on nest success, we compared the sentinel times at successful (produced at least one fledgling) and unsuccessful (depredated) nests using an analysis of covariance with group size as a covariate. We also performed a logistic regression to determine whether sentinel time predicted nest success. These analyses were performed using JMP, version 6.0 (SAS Institute, Cary, North Carolina).

To determine whether sentinels coordinated their vigilance, we first examined the lengths of bouts of sentinel duty to determine whether the probability of ending a bout is independent of its length. Such independence will result in bouts of random length, 
so a survival analysis of bout duration will produce an exponential decay function (Hailman et al. 1994). We used the SurvivalReliability platform of JMP to generate survival plots, which we tested for goodness-of-fit to exponential decay (linear fit on a semilog plot). We then compared the observed overlap (amount of time two males were sentinels simultaneously) with the expected overlap of sentinel bouts of pairs of sentinels, assuming that overlap was random with respect to whether another male was standing watch. For each pair of sentinels, the expected overlap was calculated as follows: (male 1 observed minutes as sentinel)/60 $\min \times$ (male 2 observed minutes as sentinel). We performed two comparisons. First, we restricted our analysis to the dominant and the helper that spent the most time as sentinel in 12 groups with at least one helper. Second, we used all 23 male sentinel pairs. We also used the method of McGowan and Woolfenden (1989) to calculate the expected number of "coordinated exchanges" that would occur by chance with the observed number of such exchanges. A coordinated exchange was defined as one bird terminating vigilance within $1 \mathrm{~min}$ of another bird initiating vigilance (McGowan and Woolfenden 1989). Finally, we examined the distribution of interbout intervals for evidence of coordination. Coordinated vigilance would produce homogeneous intervals between bouts of vigilance (e.g., Rodríguez-Gironés and Vásquez 2002) with an excess of short intervals (e.g., Bednekoff et al. 2008), whereas lack of coordination would produce intervals of random length. As with bout length, random intervals would produce an exponential decay function (e.g., Tolkamp and Kyriazakis 1999), which we tested using the Survival-Reliability platform of JMP.

All statistical analyses were performed using JMP. Percentages were normalized using an arcsine transformation. Results are presented as means \pm SE. Significance was accepted at $\alpha=0.05$.

\section{Results}

Prediction 1: All male members of the breeding group act as sentinels.-Both breeder and helper male Superb Fairy-wrens were vigilant (Fig. 1). Pair males (no helpers), dominants (at least one helper), and helpers did not differ significantly in amount of time as sentinel $(F=1.56, \mathrm{df}=2$ and $35, P=0.22)$.

Prediction 2: Antipredator vigilance is associated primarily with the presence of nestlings. - As shown in Figure 1, male Superb Fairy-wrens spent more time as sentinel when the nests contained nestlings than when eggs were in the nest $(F=41.2, \mathrm{df}=1$ and 35 , $P<0.0001)$. Male status and stage of the nest did not interact significantly $(F=0.38, \mathrm{df}=2$ and $35, P=0.69)$.

Prediction 3: The total amount of vigilance increases with group size.-As shown in Figure 2, time as sentinel increased significantly with increasing breeding-group size. Regression analysis yielded a regression equation of sentinel time $=12.7 \times$ number of males $+6.5\left(r^{2}=0.62, F=27.7, \mathrm{df}=1\right.$ and $\left.17, P<0.0001\right)$.

Prediction 4: Breeding males with helpers spend less time as sentinels than pairs without helpers.-Contrary to our prediction, breeding males with helpers spent more time as sentinel during our 1-h observation periods $(24.8 \pm 1.9 \mathrm{~min})$ than pair males $(16.9$ $\pm 2.5 \mathrm{~min})(t=-2.50, \mathrm{df}=17, P=0.023)$.

Prediction 5: Nests that produce fledglings (successful nests) are guarded more than depredated (unsuccessful) nests.-As shown in Figure 2, successful nests $(34.2 \pm 5.8 \%)$ were guarded

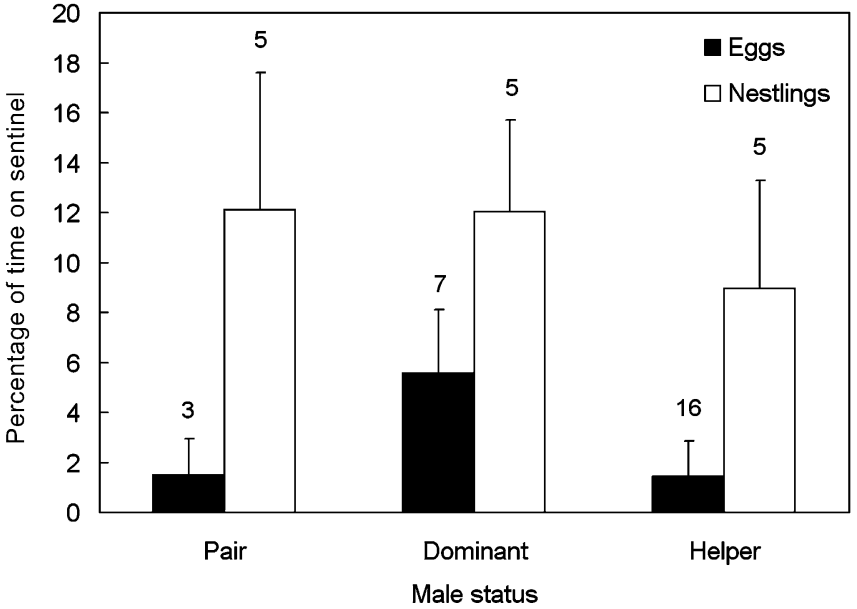

FIG. 1. When nests contained nestlings, pair (no helpers), dominant, and helper male Superb Fairy-wrens spent more time as sentinels than when eggs were present (sample sizes shown above bars). Sentinel males perched conspicuously at a location where they could see the nest (usually within $5 \mathrm{~m}$ ) and remained alert while scanning the area.

more than depredated nests $(30.3 \pm 5.5 \%)$, but this difference was marginally nonsignificant according to an analysis of covariance with group size as the covariate $(F=4.3, \mathrm{df}=1$ and $15, P=0.053)$. An inspection of Figure 2 suggests that the single group with five males had high leverage. For this reason, and because there was only one group of this size, we eliminated this point in a second analysis. The difference was again marginally nonsignificant ( $F=$ $4.0, \mathrm{df}=1$ and $14, P=0.063$ ). We also performed a logistic regression of nest outcome (depredated or successful) against the proportion of time that there was a sentinel. Sentinel time did not predict nest success $\left(\chi^{2}=0.25, \mathrm{df}=1, P=0.62\right)$.

Prediction 6: Presence of a sentinel facilitates feeding by other provisioners.-Superb Fairy-wrens were vigilant in two other

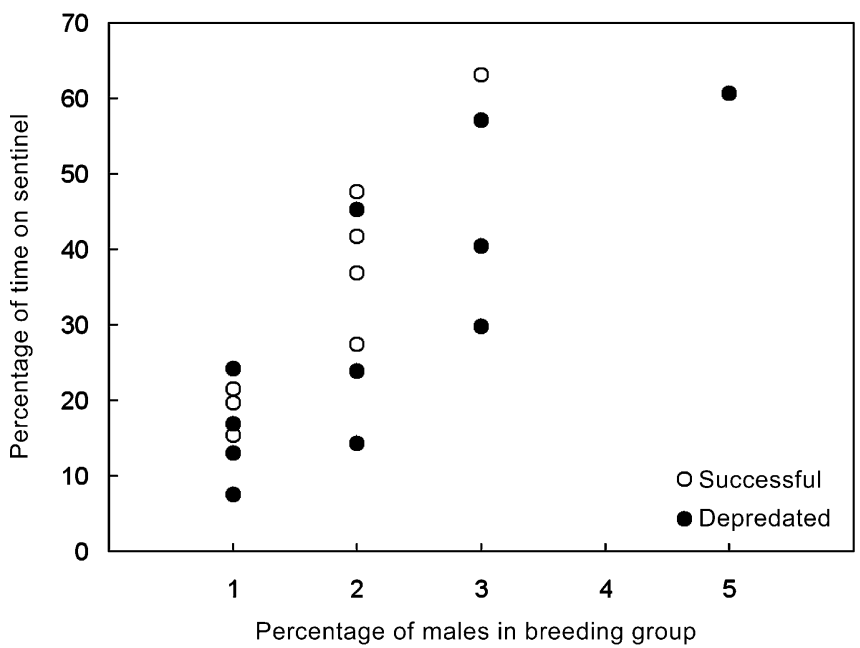

FIG. 2. Sentinel time increased with group size (breeding male plus helpers) in Superb Fairy-wrens. Times are plotted for successful nests (produced at least one fledgling) and depredated nests. 


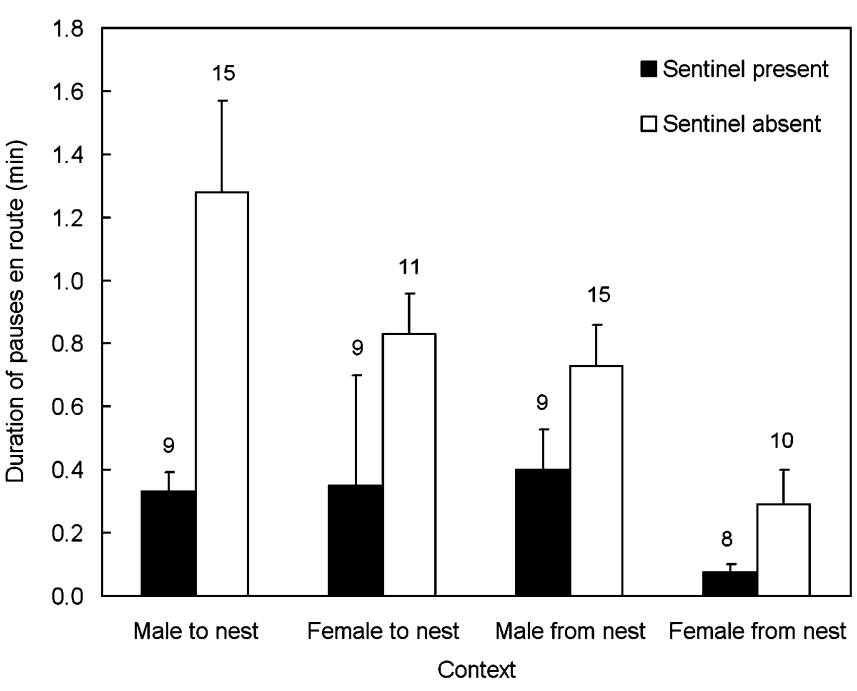

FIG. 3. Presence of a sentinel reduced the amount of time Superb Fairywrens paused to scan the area while approaching the nest to feed nestlings and when departing the nest after feeding (sample sizes shown above bars). Durations are plotted for males and females when sentinels were present and when no sentinels were present.

contexts: while approaching the nest to feed nestlings and while departing the nest after feeding, and both males and females scanned the area in these contexts. Sex of the provisioner, whether the provisioner was approaching or departing the nest, and presence of a sentinel male affected the time Superb Fairy-wrens spent pausing to scan before and after feeding nestlings (Fig. 3). An analysis of variance of sex, approaching versus departing the nest, and presence or absence of a sentinel showed that all three main effects were significant, whereas none of the interactions were significant. Males paused to scan en route significantly longer $(0.70 \pm$ $0.09 \mathrm{~min} ; F=5.22, \mathrm{df}=1$ and $77, P=0.025)$ than females $(0.38 \pm$ $0.40 \mathrm{~min}$ ), pauses on the way to the nest were significantly longer $(0.70 \pm 0.80 \mathrm{~min} ; F=5.70, \mathrm{df}=1$ and $77, P=0.019)$ than pauses while leaving the nest $(0.37 \pm 0.42 \mathrm{~min})$, and pauses en route were significantly shorter $(F=10.83, \mathrm{df}=1$ and $77, P=0.0015)$ when a sentinel was present $(0.31 \pm 0.31 \mathrm{~min})$ than when no male was sentinel $(0.77 \pm 0.80 \mathrm{~min})$ during our 1-h observation periods.

Often, currawongs seemed to be attracted to nest sites by the activity of care-giving adults, especially the males with their patches of bright blue. We made the following observations on the territory of BRA (female) and rgWW (male): 1300-1450 hours AEDT: Currawong watched BRA in bush $\sim 5 \mathrm{~m}$ from nest. 17011751 hours: Currawong searched on ground near bush used by BRA. 2235 hours: BRA scanned from cover; no currawongs in area; BRA resumed foraging at 2345 hours. 2940-3149 hours: BRA scanned area on way to nest, then resumed feeding when no currawongs were detected. 3705 hours: Currawong returned. BRA watched from cover high above nest site. rgWW departed clearing around nest area. 3910 hours: Currawong departed area. 4804 hours: BRA re-entered clearing around nest area and resumed foraging at 5009 hours. 5339-6000 hours: Two currawongs hunting in trees directly above nest. $\mathrm{rgWW}$ was foraging $\sim 5 \mathrm{~m}$ from nest but immediately moved to cover, then watched currawongs from a position where he could see the nest but that would be hard for currawongs to see from above. Male gave soft, high-pitched, thin calls until female BRA arrived to feed nestlings. BRA did not go to the nest while currawongs were present.

Prediction 7: Bouts of scanning are of random length (i.e., are of unpredictable duration), and sentinels coordinate their vigilance to provide efficient coverage.-Bouts of sentinel duty were of random length. The lengths of sentinel bouts decayed exponentially according to our log survivorship functions (Fig. 4), as shown by the fitted regression lines for the four groups with sufficient data for analysis (all $r^{2}>0.95$ ). In addition, dominant and helper males did not differ in their survivorship functions (all log-rank $\chi^{2}<1.3, \mathrm{df}=1, P>0.25$ ). When we compared expected and observed overlap times for males in groups with at least one helper, we found no evidence that sentinels coordinated their vigilance. The difference between observed and expected overlap times for all sentinel pairs $(0.10 \pm 0.92 \mathrm{~min})$ was not significant (matched pairs $t=0.11, \mathrm{df}=22, P=0.92$ ); nor was the more restrictive comparison of the dominant and the helper that performed the most sentinel time $(-1.32 \pm 1.33 \mathrm{~min})$ in groups with more than one helper (matched-pairs $t=-0.99, \mathrm{df}=11, P=$ 0.34). In addition, interbout intervals were of random length. Periods between bouts of vigilance decayed exponentially (Fig. 5), as shown by the fitted regression lines for the four groups with sufficient data for analysis (all $r^{2}>0.95$ ). By contrast, a comparison of expected and observed numbers of "coordinated exchanges" (termination and initiation within 1 min of each other) resulted in significantly more such exchanges than expected by chance (matched-pairs $t=2.62, \mathrm{df}=11, P=0.024$ ), although the difference $\left(1.05 \pm 0.40\right.$ exchanges $\left.^{-1}\right)$ was small.

\section{Discussion}

One of the most conspicuous and interesting aspects of the social system of the Superb Fairy-wren is its cooperative breeding system. In many cases, a male-female pair is assisted by one to several helper males, who are reproductively competent but assist the pair in defending the territory and caring for the young (e.g., Rowley 1965). We believe that the behavior of Superb Fairywrens supports the hypothesis that antipredator vigilance is a form of parental care within the cooperative breeding system of this species. All males in breeding groups spent at least some time scanning the area near active nests, total sentinel time increased with increasing group size, and the presence of a sentinel male seemed to facilitate feeding of nestlings. However, we found little evidence that antipredator vigilance increases nest success and only partial support for the prediction of coordination among sentinels in breeding groups with helpers. Finally, contrary to our prediction, helpers did not enable dominant males to reduce their time as sentinel; on the contrary, dominant males spent significantly more time as sentinel than males who lacked helpers.

Our observations suggest that antipredator vigilance occurs in three distinct contexts in the Superb Fairy-wren: (1) scanning while approaching a nest to feed nestlings, (2) scanning immediately after feeding nestlings, and (3) scanning between bouts of foraging. The first context could function to reduce the risk of nest predation by detecting a predator and delaying delivery of 

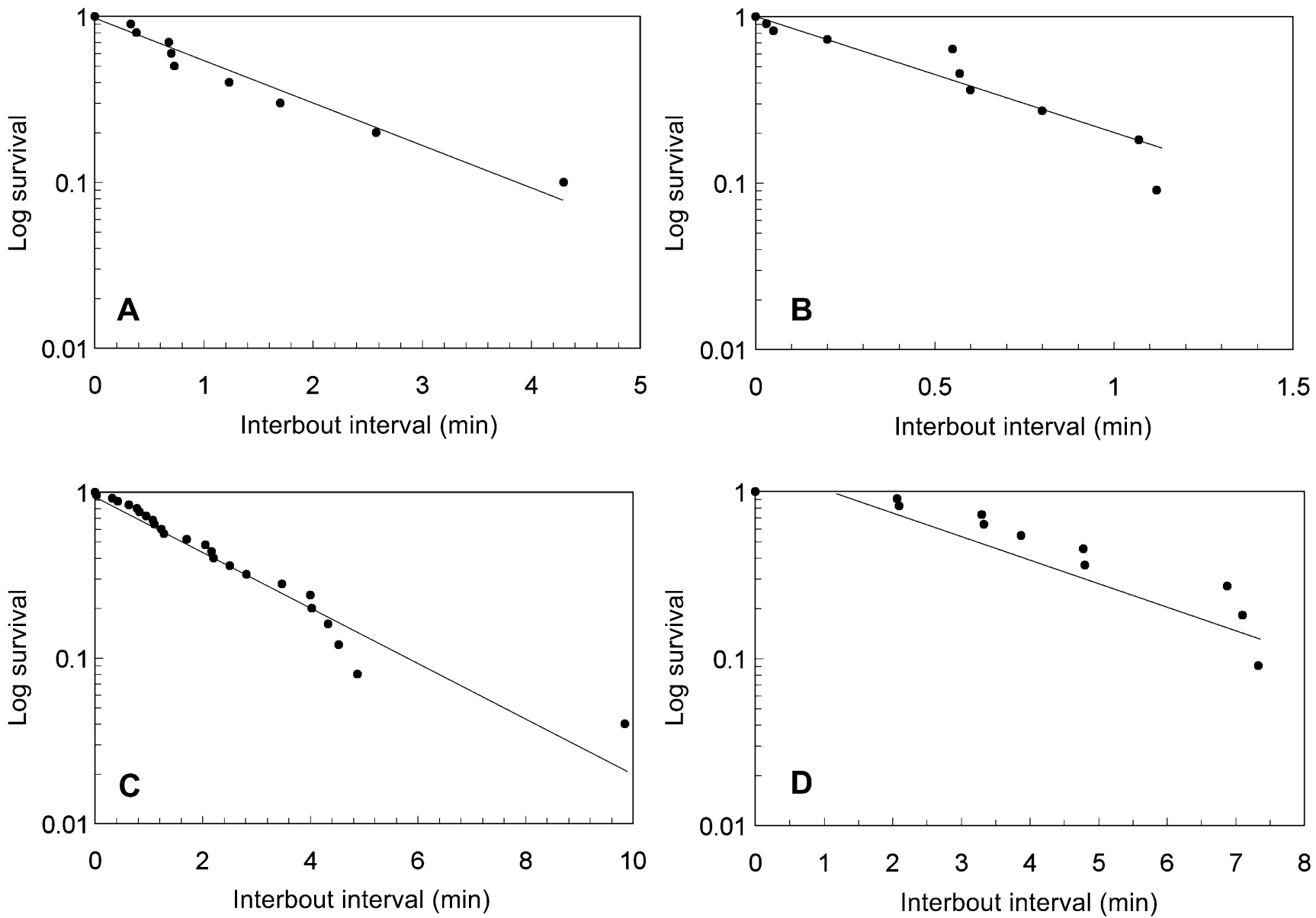

FIG. 4. Sentinel bouts of dominant and helper male Superb Fairy-wrens were of unpredictable duration, as shown by conformity with exponential decay (fitted regression lines). Plots are of survivorship curves for sentinel bout durations of dominant and helper males in four breeding groups: (A) Group brOG, (B) Group WNW, (C) Group OWO, and (D) Group BGY.

food until the risk passes. The observations that the conspicuous males pause more than females and that provisioners pause more when approaching than when departing the nest are consistent with this interpretation. This system could work without sentinels and may be of primary importance for pairs, which lack helpers. In support of this conjecture, we found that provisioners pause more when no sentinel is present than when one is present. The latter two contexts, scanning immediately after feeding nestlings and scanning between bouts of foraging, may constitute a sentinel system in which male Superb Fairy-wrens "stand watch" so that provisioners can deliver food without being observed by a visual predator. Sentinels would, thus, detect predators and warn others to delay food delivery until the predator departs.

The mechanism by which a sentinel warns a provisioner of a predator's presence is unknown but seems to involve vocalizations. Superb Fairy-wrens frequently gave a soft churr or trill, a noisy buzz, and other vocalizations while foraging near the nest and when approaching the nest. In addition to providing location information (a contact call), these vocalizations may be queries to a sentinel to determine whether he is present and whether it is safe to approach the nest (e.g., Wickler 1985, Rasa 1986). Superb
Fairy-wrens also call frequently while serving as sentinel near the nest. Wickler (1985) proposed the "watchman's song" hypothesis for sentinel behavior in babblers (Timaliidae). According to this hypothesis, sentinels use a specific vocalization (the watchman's song) to inform others that they are on guard. Hollén et al. (2008) have shown that Pied Babblers (Turdoides bicolor) use sentinel calls to announce their presence to foraging group members, which clearly benefit from an increase in biomass intake. Rasa (1986) proposed a similar vocally coordinated sentinel system in the Dwarf Mongoose (Helogale undulata), but without a specific watchman's song. Instead, a sentinel Dwarf Mongoose used a contact call (at increased volume) to announce its presence on guard. Sentinels could also signal the end of a bout of vigilance by calling, like an end-of-class bell (Gaston 1977). Bednekoff et al. (2008) examined soft calls termed "conversational gutturals" that are given by sentinel Florida Scrub-Jays but found no evidence for the "watchman's song" hypothesis or the "termination signal" hypothesis.

Both male and female Superb Fairy-wrens seem wary when approaching the nest to feed nestlings. They approach in a series of short flights, and they frequently pause along the way to scan the area. Males are more likely to pause than females, perhaps 


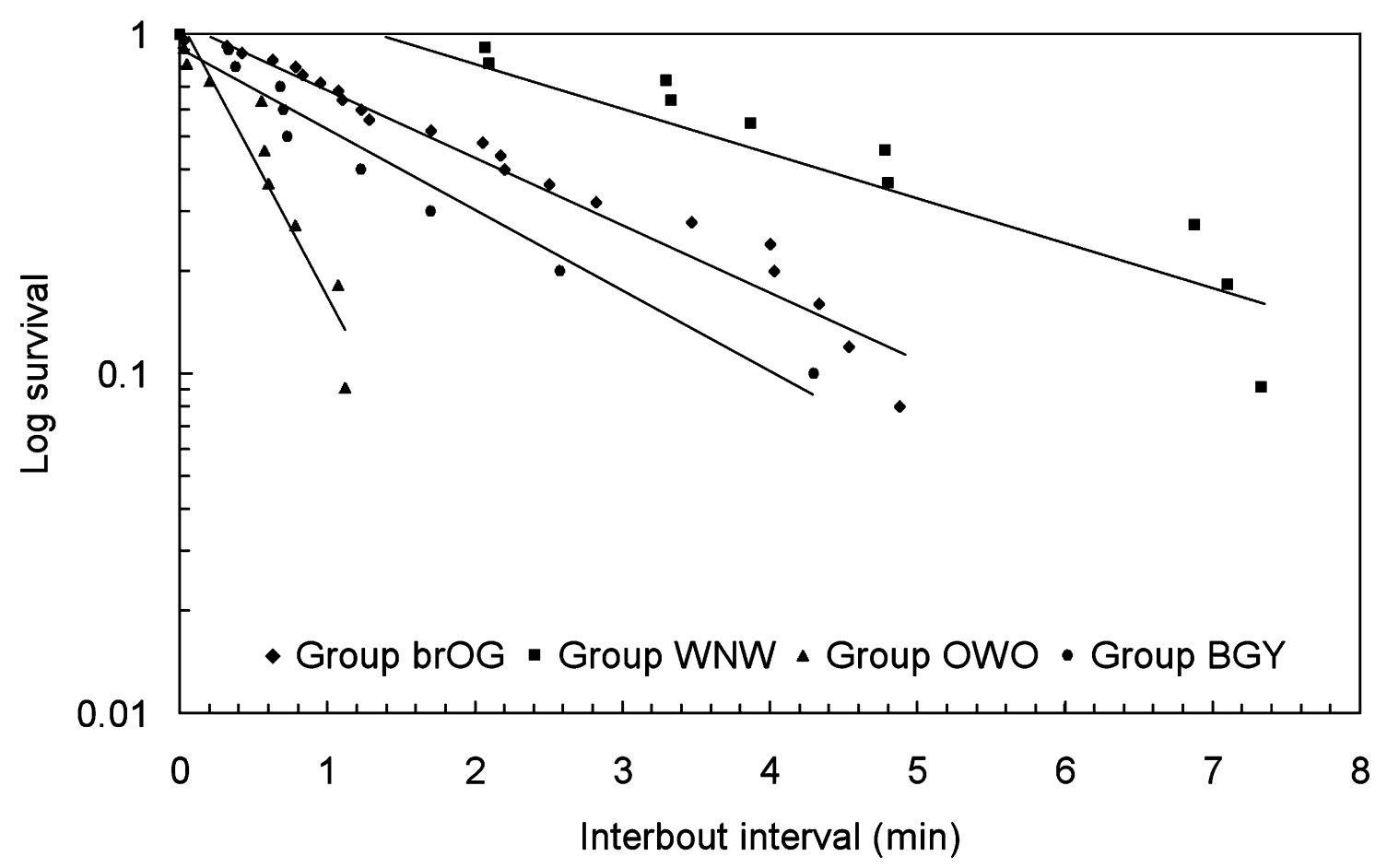

FIG. 5. Sentinel male Superb Fairy-wrens did not coordinate their exchanges, as shown by conformity of interbout durations with exponential decay (fitted regression lines). Plots are of survivorship curves for sentinel interbout durations of males in four breeding groups: (A) Group brOG, (B) Group WNW, (C) Group OWO, and (D) Group BGY.

because they are more conspicuous to predators. When a human observer is close to an active nest, neither the males nor the female will approach the nest. We have observed cases in which perched currawongs were detected by provisioning Superb Fairy-wrens, which then avoided their nest sites until the currawongs departed. It seems unlikely that a 10-g Superb Fairy-wren could successfully drive away a much larger currawong once it discovers a nest, but sentinels may make nest discovery less likely. We found little evidence, however, that sentinel behavior reduced currawong predation on nestlings. Although predation by currawongs is an important source of nest failure today, currawongs were unknown in the Canberra area until the mid-1970s (Taylor 1992), so perhaps Superb Fairy-wrens and currawongs are an example of evolutionary lag (e.g., Rothstein 1975, Ward et al. 1996).

Superb Fairy-wrens are also know to perform a "rodent run" display (Rowley 1962), which may function to draw a predator away from a nest site. Pied Babblers give purr calls when feeding both nestlings and fledglings, but they also use these calls to lead fledglings away from predators (Raihani and Ridley 2007). Considerably more research will be necessary to identify the mechanisms by which antipredator vigilance functions in Superb Fairy-wrens and other species.

Although many vigilance systems lack coordination among group members (see Ward 1985, Bednekoff and Lima 1998), coordination of sentinels has been claimed for cooperatively breeding species (e.g., Andrews and Naik 1970, Gaston 1977, Rasa 1977, Moran 1984, McGowan and Woolfenden 1989, Wright et al. 2001, Bednekoff and Woolfenden 2003) and is expected when group members scan from exposed locations, predation risk is high, group size is small, and group members do not need to check visually for the presence of a sentinel (Ward 1985, Wickler 1985, Bednekoff 1997). Thus, coordinated vigilance would seem to be advantageous for Superb Fairy-wrens, but we have little evidence for such coordination. Bednekoff and Lima (1998) discussed the possible importance of unpredictability to the benefit of sentinel behavior when predators stalk their prey, and Hailman et al. (1994) showed that lengths of Florida Scrub-Jay sentinel bouts were random. Models of antipredator vigilance, however, have focused on randomness of inter-scan intervals; surprisingly little attention has been paid to antipredator scans themselves (see Bednekoff and Lima 1998). Superb Fairy-wrens and Florida Scrub-Jays, two cooperatively breeding birds, seem similar in that the probability of terminating a sentinel bout was independent of the length of that bout, but although McGowan and Woolfenden (1989) and Bednekoff and Woolfenden (2003) found good evidence for coordinated vigilance in Florida Scrub-Jays, and despite a small excess in "coordinated exchanges," at this point we conclude that vigilant Superb Fairy-wrens act independently.

Hailman et al. (1994) argued that helpers would reduce the need for breeding Florida Scrub-Jays to act as sentinels, thus allowing them more time to forage, though they observed this effect only during the non-breeding season. We found no evidence of this effect in Superb Fairy-wrens with nestlings; on the contrary, we observed that males with helpers spent significantly more time as sentinel than males without helpers. We do not believe that this effect occurs because pair males value their broods less than males with helpers. On the contrary, pair males may have more at stake because they are at greater risk of cuckoldry than males 
with helpers (Mulder et al. 1994, Dunn and Cockburn 1996). In addition, Dunn and Cockburn (1996) showed that dominant male Superb Fairy-wrens reduce provisioning in the presence of helpers, all of which feed nestlings, so perhaps dominant males allocate more time for sentinel behavior because helpers free them, to some extent, from feeding nestlings. We should note that sentinel behavior may vary or have different effects during different phases of the annual cycle (e.g., non-breeding, nest building, incubation, nestlings, fledglings) and that such differences make interspecific comparisons difficult if studies are conducted during different phases.

In addition to feeding young, helper male Superb Fairy-wrens also provided antipredator vigilance, and, as a result, total sentinel time increased with number of males available to guard the nest. Hailman et al. (1994) found a similar increase during nesting in Florida Scrub-Jays, but Ferguson (1987) found no such effect in White-browed Sparrow-weavers (Plocepasser mahali). Finally, the additional sentinel time contributed by helpers did not appear to reduce predation by currawongs on Superb Fairy-wren nests. This paradoxical result supports the conclusion of Cockburn et al. (2008b) that the breeding pair gains no immediate reproductive advantage from supernumeraries. Future studies of the Superb Fairy-wrens could focus on why supernumeraries provide help in the form of feeding and guarding nestlings (e.g., Mulder and Langmore 1993) and why dominant males tolerate helpers (Cockburn et al. 2008b).

\section{ACKNOWLEDGMENTS}

We are grateful for the assistance of the wren crew: D. Green, R Cooney, D. McLaughlin, C. Coddington, and K. Chan, as well as P. Dunn, L. Whittingham, B. Newton, and the staff of the Australian National Botanic Gardens, without whom this research could not have been conducted. We also thank J. P. Hailman, D. B. McDonald, and an anonymous reviewer for helpful comments on earlier drafts of this paper.

\section{Literature Cited}

ANDREWS, M. I., AND N. M. NAIK. 1970. The biology of the Jungle Babbler. Pavo 8:1-34.

BeDNeKoff, P. A. 1997. Mutualism among safe, selfish sentinels: A dynamic game. American Naturalist 150:373-392.

Bednekoff, P. A., R. Bowman, AND G. E. Woolfenden. 2008. Do conversational gutturals help Florida Scrub-Jays coordinate their sentinel behavior? Ethology 114:313-317.

BEDNEKOFF, P. A., AND S. L. LiMA. 1998. Randomness, chaos and confusion in the study of antipredator vigilance. Trends in Ecology and Evolution 13:284-287.

BedneKoff, P. A., ANd G. E. Woolfenden. 2003. Florida ScrubJays (Aphelocoma coerulescens) are sentinels more when well-fed (even with no kin nearby). Ethology 109:895-903.

Caraco, T. 1982. Flock size and the organization of behavioral sequences in juncos. Condor 84:101-105.

COCKBURN, A. 1998. Evolution of helping behavior in cooperatively breeding birds. Annual Review of Ecology and Systematics 29:141-177.
Cockburn, A., H. L. Osmond, R. A. Mulder, M. C. Double, And D. J. GreEn. 2008a. Demography of male reproductive queues in cooperatively breeding Superb Fairy-wrens Malurus cyaneus. Journal of Animal Ecology 77:297-304.

Cockburn, A., R. A. Sims, H. L. Osmond, D. J. Green, M. C. Double, ANd R. A. Mulder. 2008b. Can we measure the benefits of help in cooperatively breeding birds: The case of Superb Fairy-wrens Malurus cyaneus? Journal of Animal Ecology 77: $430-438$.

Double, M. [C.], And A. Cockburn. 2000. Pre-dawn infidelity: Females control extra-pair mating in Superb Fairy-wrens. Proceedings of the Royal Society of London, Series B 267:465-470.

Double, M. C., D. Dawson, T. Burke, and A. Cockburn. 1997. Finding the fathers in the least faithful bird: A microsatellitebased genotyping system for the Superb Fairy-wren Malurus cyaneus. Molecular Ecology 6:691-693.

Double, M. C., R. Peakall, N. R. Beck, and A. Cockburn. 2005. Dispersal, philopatry, and infidelity: Dissecting local genetic structure in Superb Fairy-wrens (Malurus cyaneus). Evolution 59:625-635.

DugatKin, L. A.1997. Cooperation among Animals: An Evolutionary Perspective. Oxford University Press, Oxford, United Kingdom.

DunN, P. O., AND A. COCKBURN. 1996. Evolution of male parental care in a bird with almost complete cuckoldry. Evolution 50:25422548.

Dunn, P. O., A. Cockburn, And R. A. Mulder. 1995. Fairy-wren helpers often care for young to which they are unrelated. Proceedings of the Royal Society of London, Series B 259:339-343.

EMLEN, S. T.1995. An evolutionary theory of the family. Proceedings of the National Academy of Sciences USA 92:8092-8099.

EmLen, S. T., AND P. H. Wrege. 1992. Parent-offspring conflict and the recruitment of helpers among bee-eaters. Nature 356:331333.

Ferguson, J. W. H. 1987. Vigilance behaviour in White-browed Sparrow-weavers Plocepasser mahali. Ethology 76:233-235.

Gaston, A. J. 1977. Social behaviour within groups of Jungle Babblers (Turdoides striatus). Animal Behaviour 25:828-848.

Goodwin, D. 1976. Crows of the World. Cornell University Press, Ithaca, New York.

Griffin, A. S., AND S. A. West. 2003. Kin discrimination and the benefit of helping in cooperatively breeding vertebrates. Science 302:634-636.

Hailman, J. P., K. J. McGowan, and G. E. Woolfenden. 1994. Role of helpers in the sentinel behaviour of the Florida scrub jay (Aphelocoma c. coerulescens). Ethology 97:119-140.

Hollén, L. I., M. B. V. Bell, AND A. N. RAdFord. 2008. Cooperative sentinel calling? Foragers gain increased biomass intake. Current Biology 18:576-579.

MAJOR, R. E., G. Gowing, AND C. E. KendAL. 1996. Nest predation in Australian urban environments and the role of the Pied Currawong, Strepera graculina. Australian Journal of Ecology 21:399-409.

McGowan, K. J., ANd G. E. WoOlfenden. 1989. A sentinel system in the Florida scrub jay. Animal Behaviour 37:1000-1006.

Moran, G. 1984. Vigilance behaviour and alarm calls in a captive group of meerkats, Suricata suricatta. Zeitschrift für Tierpsychologie 65:228-240.

Mulder, R. A., P. O. Dunn, A. Cockburn, K. A. Lazenby-Cohen, AND M. J. Howell. 1994. Helpers liberate female fairy-wrens 
from constraints on extra-pair mate choice. Proceedings of the Royal Society of London, Series B 255:223-229.

Mulder, R. A., AND N. E. LANGMORE. 1993. Dominant males punish helpers for temporary defection in Superb Fairy-wrens. Animal Behaviour 45:830-833.

Prawiradilaga, D. M. 1996. Foraging ecology of Pied Currawongs Strepera graculina in recently colonised areas of their range. Ph.D. dissertation, Australian National University, Canberra.

Pulliam, H. R. 1973. On the advantages of flocking. Journal of Theoretical Biology 38:419-422.

Raihani, N. J., AND A. R. Ridley. 2007. Adult vocalizations during provisioning: Offspring response and postfledging benefits in wild Pied Babblers. Animal Behaviour 74:1303-1309.

RASA, O. A. E. 1977. The ethology and sociology of the dwarf mongoose (Helogale undulata rufula). Zeitschrift für Tierpsychologie 43:337-406.

RASA, O. A. E. 1986. Coordinated vigilance in dwarf mongoose family groups: The 'watchman's song' hypothesis and the costs of guarding. Ethology 71:340-344.

RodríGuez-Gironés, M. A., AND R. A. VÁSQUez. 2002. Evolutionary stability of vigilance coordination among social foragers. Proceedings of the Royal Society of London, Series B 269:1803-1810.

Rothstein, S. I. 1975. An experimental and teleonomic investigation of avian brood parasitism. Condor 77:250-271.

ROW LEY, I. 1962. "Rodent-run" distraction display by a passerine, the Superb Blue Wren Malurus cyaneus (L.). Behaviour 19:170-176.

Rowley, I. 1965. The life history of the Superb Blue Wren Malurus cyaneus. Emu 64:251-297.
Russell, A. F., N. E. LAngmore, A. Cockburn, L. B. Astheimer, ANd R. M. KiLNER. 2007. Reduced egg investment can conceal helper effects in cooperatively breeding birds. Science 317:941-944.

Stacey, P. B., And W. D. Koenig. 1990. Cooperative Breeding in Birds: Long-term Studies of Ecology and Behavior. Cambridge University Press, Cambridge, United Kingdom.

TAYLOR, M. 1992. Birds of the Australian Capital Territory: An Atlas. Canberra Ornithologists Group and National Capital Planning Authority, Canberra, Australia.

Tolkamp, B. J., AND I. Kyriazakis. 1999. To split behaviour into bouts, log-transform the intervals. Animal Behaviour 57:807817.

Ward, D., A. K. Lindholm, AND J. N. M. Smith. 1996. Multiple parasitism of the Red-winged Blackbird: Further experimental evidence of evolutionary lag in a common host of the Brown-headed Cowbird. Auk 113:408-413.

WARD, P. I. 1985. Why birds in flocks do not coordinate their vigilance periods. Journal of Theoretical Biology 114:383-385.

WICKLER, W. 1985. Coordination of vigilance in bird groups. The 'watchman's song' hypothesis. Zeitschrift für Tierpsychologie 69: 250-253.

WoOLFENDEN, G. E. 1975. Florida scrub jay helpers at the nest. Auk 92:1-15.

Wright, J., E. Berg, S. R. De Kort, V. Khazin, and A. A. MaklaKOV. 2001. Cooperative sentinel behaviour in the Arabian Babbler. Animal Behaviour 62:973-979.

Associate Editor: D. B. McDonald 